\title{
Assessment of requests for medication- related follow-up after hospital discharge, and the relation to unplanned hospital revisits, in older patients: a multicentre retrospective chart review
}

Henrik Cam ${ }^{1,2^{*}}$, Thomas Gerardus Hendrik Kempen ${ }^{2,3}$, Helena Eriksson², Kanar Abdulreda², Kristin Franzon ${ }^{4,5}$ and Ulrika Gillespie ${ }^{1,2}$

\begin{abstract}
Background: The discharge of older hospitalised patients is critical in terms of patient safety. Inadequate transfer of information about medications to the next healthcare provider is a known problem, but there is a lack of understanding of this problem in settings where shared electronic health records are used.

The aims of this study were to evaluate the prevalence of patients for whom hospitals sent adequate requests for medication-related follow-up at discharge, the proportion of patients with unplanned hospital revisits because of inadequate follow-up requests, and the association between medication reviews performed during hospitalisation and adequate or inadequate follow-up requests.

Methods: We conducted a retrospective chart review. The study population was randomly selected from a clusterrandomised crossover trial which included patients 65 years or older who had been admitted to three hospitals in Sweden with shared electronic health records between hospital and primary care. Each patient was assessed with respect to the adequacy of the request for follow-up. For patients where the hospitals sent inadequate requests, data about any unplanned hospital revisits were collected, and we assessed whether the inadequate requests had contributed to the revisits. The association between medication reviews and adequate or inadequate requests was analysed with a Chi-square test.

Results: A total of 699 patients were included. The patients' mean age was 80 years; an average of 10 medications each were prescribed on hospital admission. The hospitals sent an adequate request for 418 (60\%) patients. Thirtyeight patients (14\%) had a hospital revisit within six months of discharge which was related to an inadequate request. The proportion of adequate or inadequate requests did not differ between patients who had received a medication review during hospitalisation and those who had not $(p=0.83)$.
\end{abstract}

Conclusions: The prevalence of patients for whom the hospitals sent adequate follow-up requests on discharge was low. More than one in every ten who had an inadequate request revisited hospital within six months of discharge for

*Correspondence: henrik.cam@farmaci.uu.se

2 Department of Pharmacy, Uppsala University, Uppsala, Sweden

Full list of author information is available at the end of the article

(c) The Author(s) 2021. Open Access This article is licensed under a Creative Commons Attribution 4.0 International License, which permits use, sharing, adaptation, distribution and reproduction in any medium or format, as long as you give appropriate credit to the original author(s) and the source, provide a link to the Creative Commons licence, and indicate if changes were made. The images or other third party material in this article are included in the article's Creative Commons licence, unless indicated otherwise in a credit line to the material. If material is not included in the article's Creative Commons licence and your intended use is not permitted by statutory regulation or exceeds the permitted use, you will need to obtain permission directly from the copyright holder. To view a copy of this licence, visit http://creativecommons.org/licenses/by/4.0/. The Creative Commons Public Domain Dedication waiver (http://creativeco mmons.org/publicdomain/zero/1.0/) applies to the data made available in this article, unless otherwise stated in a credit line to the data. 
reasons related to the request. Medication reviews conducted during hospitalisation did not affect the proportion of adequate or inadequate requests sent. A communication gap still exists despite the usage of a shared electronic health record between primary and secondary care levels.

Keywords: Aged, Aftercare, Continuity of patient care, Electronic health records, Hospitalisation, Patient discharge, Patient transfer, Pharmaceutical services, Patient safety, Referral and consultation

\section{Background}

Medications are the cause of up to $20 \%$ of all hospitalisations, including hospital revisits $[1,2]$. Older patients have a high risk of adverse drug events (ADEs) primarily due to a high disease burden and consequent complex medication treatment [3]. The transition-of-care process, which is defined as a patient transferring to or returning from one healthcare setting to another, has been identified by the World Health Organization as a main area of focus for improving patient safety [4]. Specifically, the discharge of hospitalised patients has been identified as critical in terms of patient safety, mainly because of the increased risk of ADEs, and deficits in communication and information transfer between hospitals and primary care providers (PCPs) $[4,5]$. Changes in patients' medications are frequently made during hospitalisation [6]. This necessitates adequate follow-up planning and measures post-discharge, to prevent ADEs from occurring [7-10]. To increase patient safety, it is also of great importance to adequately involve and inform the patients about their medications and related decisions [11].

Discharge summaries are commonly used as a communication tool by the hospitals to communicate with the next healthcare provider and the patient $[12,13]$. The discharge summary is transferred to the PCP and should include specific requests for active follow-up on the medication changes after discharge where necessary $[14,15]$. The timely transfer of this discharge summary with clear requests for follow-up is considered crucial for PCPs to be able to process the information [16]. However, discharge summaries are commonly delayed, of deficient quality and contain incomplete information regarding follow-up plans [17, 18]. A shared electronic health record (EHR) between hospital and primary care has been proposed as a solution to these problems [19-21]. These shared EHRs, including shared medication lists, have been implemented in several regions in Sweden. Consequently, medical notes and discharge documents do not need to be transferred and can be accessed instantly by PCPs. However, in order for the PCPs to be notified and to actively follow up on the medication changes after patient discharge, the hospital physician (HP) is usually required to send an electronic referral (i.e. an MRR - medication-related referral), in addition to writing the discharge summary, to request that the PCP accepts the responsibility of performing the follow-up [22]. These requests for medication-related follow-up for specific patients are central to the hospitals' follow-up planning. There are to our knowledge no previous studies evaluating these requests for medication-related follow-up sent at hospital discharge in a setting where a shared EHR is used. It is important to understand this aspect of medicationrelated information transfer at hospital discharge for the development of future interventions to improve the transition-of-care process.

One intervention which has been proposed to reduce medication-related morbidity is to undertake a comprehensive medication review (CMR) during hospitalisation [23-25]. The purpose is to optimise a patient's medication treatment, to enable the best possible outcome and to minimise medication-related harm, by examining the pharmacotherapy in a structured and critical manner together with the patient [26]. Drugrelated problems (DRPs), which potentially can result in ADEs, are identified and solved through the CMR process [27]. CMRs can result in more changes in the medication treatment and the identification of DRPs that should be resolved and/or followed-up in primary care than if a CMR is not performed. Consequently, it is of importance to have a thorough information transfer to the next healthcare provider. There is therefore a need to explore the impact of CMRs on information transfer at hospital discharge.

The primary aims of this study were to evaluate the prevalence of patients for whom hospitals sent adequate requests for medication-related follow-up at hospital discharge, regardless of the presence of a CMR during hospitalisation, and the proportion of patients who had an unplanned hospital revisit which could be related to an inadequate follow-up request. We also aimed to determine if there was an association between CMRs performed during hospitalisation and adequate or inadequate follow-up requests.

\section{Methods}

\section{Study design and setting}

This multicentre, retrospective study involved a review of the charts of patients admitted to Uppsala University 
Hospital, Enköping Hospital and Västerås Central Hospital in Sweden. Data collection and analyses were performed between September 2019 and September 2020.

Patients were selected from a multicentre, cluster-randomised, crossover trial (MedBridge) conducted between 2017 and 2018 at four Swedish hospitals: the hospitals in Uppsala, Enköping, Västerås and Gävle [28]. The aim of the trial was to study the effects of pharmacist-initiated hospital-based CMRs, including active follow-up, on older patients' healthcare utilisation. Patients in the intervention groups had a pharmacist-initiated CMR, including a medication reconciliation before discharge, during hospitalisation and were compared with control patients without a CMR. In addition, the pharmacists had the possibility to send an MRR to the PCP at discharge in one of the intervention groups. The criteria for inclusion in the trial were patients aged 65 years or older and were admitted to one of the participating wards. A total number of 2637 patients were included. The incidence of unplanned hospital revisits within 12 months did not differ between the intervention groups and the control group [28]. A process evaluation of the trial [29] showed that in less than half of the intervention patients (46\%), the CMR included a medication reconciliation at discharge. The pharmacist sent an MRR in only $6 \%$ of the patients in the intervention group that included this possibility. Furthermore, $15 \%$ of the control patients were contaminated, i.e. having received either a medication reconciliation or a CMR during hospitalisation.

The three hospitals included in this chart review are the hospitals of Uppsala and Enköping in Uppsala region and the hospital of Västerås in Västmanland region. These regions contain around 370,000 and 270,000 inhabitants, respectively [30]. The fourth hospital in the MedBridge trial, the hospital of Gävle, was excluded due to the use of an EHR system without the possibility to send electronic referrals to primary care. All three included hospitals use the same EHR system (Cambio Cosmic ${ }^{\circledR}$, which is also used by most primary care centres in these regions). Requests for follow-up after hospital discharge are usually communicated by HPs to the next healthcare provider by sending electronic referrals through the EHR. The receiver/next healthcare provider then needs to respond to the referral by accepting or declining it. There is one exception to this system: sometimes an internal request (not sent via the EHR) is used when follow-up for the patient is planned with an outpatient specialist unit at the same hospital clinic from which the patient was discharged. When the MedBridge trial was initiated, the possibility for ward-based pharmacist to also send MRRs was introduced at the hospitals.

According to Swedish legislation, the discharge documents related to medications should consist of a discharge summary, a discharge letter with a medication report, and an updated medication list [12, 13]. These documents should be written in the patient's EHR and sent to the next healthcare provider and the patient on the day of discharge. In both regions, these documents are available on the shared EHR, but the PCP is not actively notified when the discharge documents have been written.

\section{Study population and randomisation}

The 2041 patients included in the MedBridge trial from the hospitals of Uppsala, Enköping and Västerås were eligible for inclusion in our study (Fig. 1). The eligible patients were stratified by hospital and randomly selected using Microsoft Excel ${ }^{\circledR}$ to generate random lists regardless of which study group the patient belonged to in the MedBridge trial. The following exclusion criteria were applied: deceased during hospitalisation or receiving palliative care on discharge. The inclusion process was stopped when one third of the eligible patients were included.

\section{Main outcomes}

The main outcomes were proportion of patients with adequate and inadequate requests for follow-up and proportion of patients who had an unplanned hospital revisit within six months after hospital discharge which could be related to an inadequate follow-up request.

\section{Data collection}

\section{Detection of MRRs}

Basic demographic data, hospital length of stay, medications at admission, previous medical history, data about which patients received a CMR during hospitalisation, and had an MRR sent to their PCP had already been collected for all participants in the MedBridge trial. This data-collection step had been performed by research assistants manually assessing the patients' EHRs. An MRR sent to the PCP was defined as an electronic referral with a request for follow-up concerning the patient's medications that was sent to the PCP at discharge. We also checked the records of all patients for whether an MRR had been sent via the EHR to any outpatient specialist unit at discharge. If the discharge summary mentioned that follow-up of the medications was planned for an outpatient specialist unit belonging to the same clinic as the ward from which the patient was discharged (without a referral in the EHR), this was classified as an MRR that had been sent.

\section{Assessment of requests for follow-up}

A comprehensive assessment of the adequacy of the request for follow-up was carried out for each patient. 


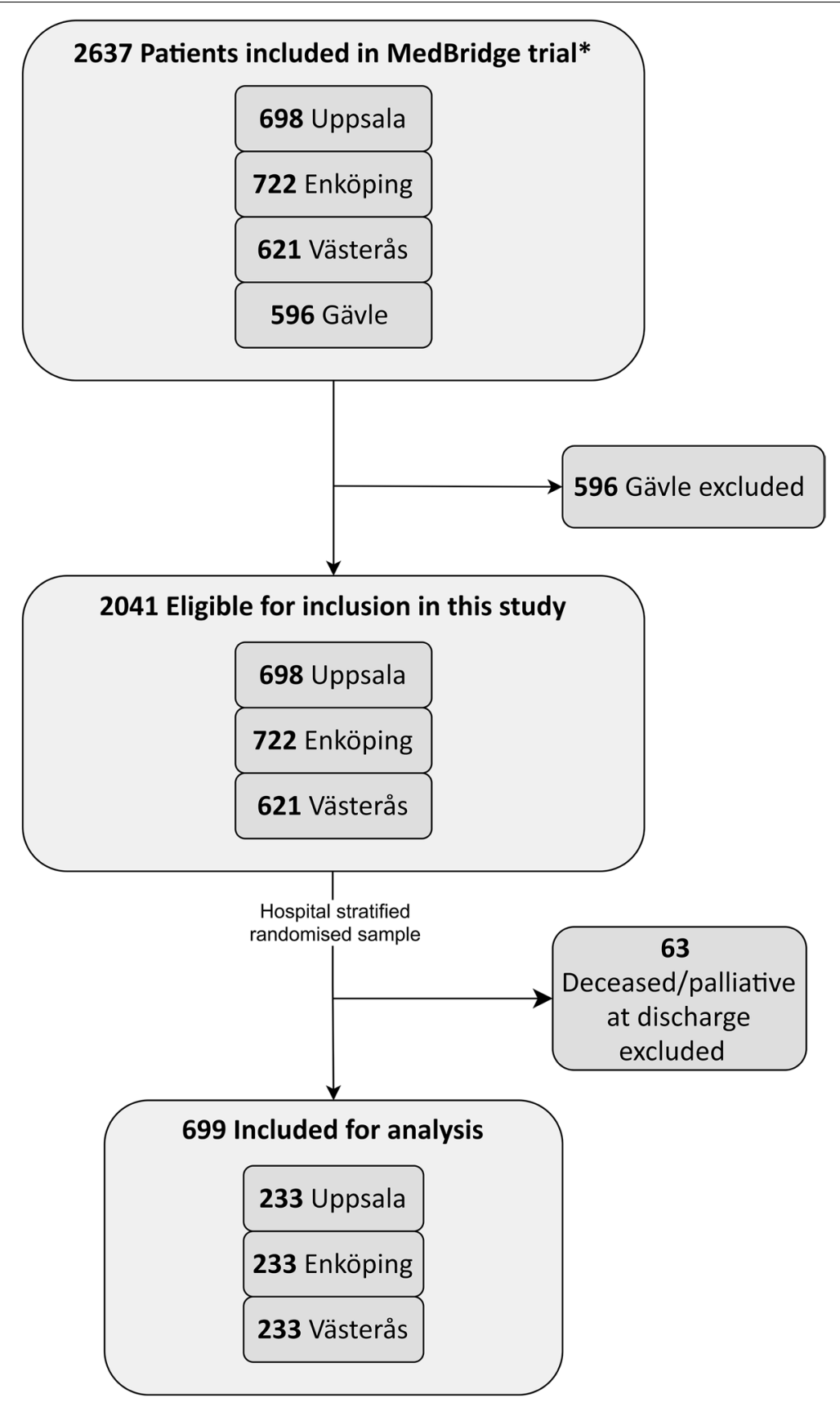

Fig. 1 Flowchart of participants in the study. Values in each box are numbers of patients. * A multicentre, cluster-randomised, crossover trial [28]

This was done by comparing the content of all the MRRs sent for each patient with the information available on the medication list and all written documentation by healthcare professionals in the EHR during hospitalisation. A request for follow-up was classified into four different categories: 1 ) adequate - complete MRRs sent 2) adequate - no MRRs sent, not needed 3) inadequate - incomplete MRRs sent and 4) inadequate - no MRRs sent, but needed. A request was deemed as "inadequate - incomplete MRRs sent" if the MRRs did not mention all the medication changes that needed follow-up or did not mention all relevant unresolved DRPs identified during hospitalisation, despite a statement in the EHR that the DRP would be communicated to the next healthcare provider. A medication change was defined as a medication being stopped or started or a change of dosage or 
formulation during hospitalisation, with the change lasting after discharge. A request was deemed as "inadequate - no MRRs sent, but needed" when no MRR had been sent and the assessment concluded that an MRR should have been sent to ensure adequate follow-up. The discharge summaries and discharge letters for the identified internal MRRs were also reviewed for follow-up requests and actions taken concerning medications.

\section{Assessment of unplanned hospital revisits}

Data were collected from the EHR about any unplanned hospital revisits (hospitalisations or emergency department visits) within six months of hospital discharge for patients with an inadequate request for follow-up. The EHR was also checked for follow-up actions taken by the PCP or outpatient specialist unit for these patients with an inadequate request. The reason for this was to confirm that no adequate actions had been taken despite the inadequate request. Based on this information an assessment was made whether the inadequate request (resulting in no or inadequate follow-up actions) was likely to have contributed to the unplanned revisit. Consequently, the revisits were classified as related or unrelated to the inadequate request. Only the first unplanned hospital revisit after hospital discharge could be classified as related to the inadequate request. The reason behind this was that additional changes in the medication treatment could have been made as a result of the revisit. Thus, each patient could only have one unplanned hospital revisit related to the inadequate request.

\section{Data collectors and assessors}

Data collection and assessments were made by either one senior clinical pharmacist (UG or $\mathrm{HC}$ ) or one of two final-year pharmacy students (HE or KA) who were trained and supervised by HC. Any cases where a conclusion could not be drawn were discussed within an internal expert panel consisting of HC, UG and a physician specialising in geriatrics (KF). A decision was made when consensus was reached in each case.

\section{Statistical analysis}

Data were analysed using descriptive statistics and are presented with a confidence interval of $95 \%$ where applicable. The association between CMRs performed during hospitalisation and inadequate or adequate requests for follow-up was analysed with a Chi-square test of independence $(\alpha=0.05)$. All statistical analyses were made in Microsoft Excel.

\section{Ethics approval}

All procedures involving data from human participants in this study were carried out in concordance with the ethical standards of Swedish legislation and the WMA declaration of Helsinki [31]. Informed written consent was obtained from all participants in the MedBridge trial. The trial was approved by the Swedish Central Ethical Review Board (CEPN; registration number: Ö21-2016).

\section{Results}

Out of 2041 eligible patients, 762 were randomised for inclusion. Sixty-three patients $(8 \%)$ were deceased or in a palliative stage at discharge and were excluded. This resulted in a total of 699 included patients. The baseline characteristics of the study population are shown in Table 1 . The mean age of the study population was 80 (standard deviation, SD, \pm 8$)$ years, $50 \%(n=218)$ were female, had an average of $10(\mathrm{SD} \pm 6)$ prescribed medications, $68 \%(n=476)$ had $\geq 3$ diagnoses, the median duration of hospitalisation was 7 (interquartile range 4-12) days, and 437 (63\%) had had a CMR during hospitalisation.

Out of all the patients, 600 (86\%) had at least one medication change during hospitalisation (Table 2). The mean number of medication changes was $3(\mathrm{SD} \pm 3)$. An MRR was sent only to the PCP for 201 (29\%) patients, only to

Table 1 Baseline characteristics of included patients

\begin{tabular}{|c|c|c|}
\hline Characteristics & $\begin{array}{l}\mathrm{n} \\
\text { (total }=699 \text { ) }\end{array}$ & $\%$ \\
\hline Age, mean years (SD) & $80( \pm 8)$ & N/A \\
\hline Female sex & 351 & 50 \\
\hline \multicolumn{3}{|l|}{ Social support } \\
\hline Home care & 179 & 26 \\
\hline Nursing home & 81 & 12 \\
\hline Medications at admission, mean number (SD) & $10( \pm 6)$ & N/A \\
\hline Automated dose-dispensed medications & 183 & 26 \\
\hline Hospitalisation duration, median days (IQR) & $7(4-11)$ & N/A \\
\hline eGFR (ml/min) upon admission, mean (SD) & $50(25)$ & N/A \\
\hline \multicolumn{3}{|l|}{ CMR during hospitalisation } \\
\hline Yes & 437 & 63 \\
\hline No & 262 & 37 \\
\hline \multicolumn{3}{|l|}{ Number of diagnoses in medical history } \\
\hline None & 8 & 1 \\
\hline$\geq 3$ & 476 & 68 \\
\hline$\geq 6$ & 103 & 15 \\
\hline \multicolumn{3}{|l|}{ Hospital } \\
\hline Uppsala & 233 & 33 \\
\hline Enköping & 233 & 33 \\
\hline Västerås & 233 & 33 \\
\hline
\end{tabular}

Abbreviations: CMR comprehensive medication review, eGFR estimated glomerular filtration rate, $I Q R$ interquartile range, $S D$ standard deviation 
Table 2 Measures related to medication-related requests for follow-up

\begin{tabular}{|c|c|c|}
\hline Measures & $\begin{array}{l}\mathrm{n} \\
\text { (total }=699)\end{array}$ & $\begin{array}{l}\% \\
(95 \% \mathrm{Cl})\end{array}$ \\
\hline \multicolumn{3}{|l|}{ Medication changes } \\
\hline Mean number (SD) & $3( \pm 3)$ & N/A \\
\hline At least one medication change & 600 & $86(83-88)$ \\
\hline \multicolumn{3}{|l|}{ Sending of MRR } \\
\hline MRR sent only to PCP & 201 & $29(25-32)$ \\
\hline MRR sent only to hospital outpatient unit & 189 & $27(24-30)$ \\
\hline MRR sent to both PCP and hospital outpatient unit & 69 & $10(8-12)$ \\
\hline No MRR sent & 240 & $34(31-38)$ \\
\hline \multicolumn{3}{|l|}{ Assessment of request for follow-up } \\
\hline Adequate request for follow-up & 418 & $60(56-63)$ \\
\hline Complete MRRs sent & 292 & $42(36-48)$ \\
\hline No MRR sent, not needed & 126 & $18(14-22)$ \\
\hline Inadequate request for follow-up & 281 & $40(37-44)$ \\
\hline Incomplete MRRs sent & 167 & $24(19-29)$ \\
\hline No MRR sent, but needed & 114 & $16(13-20)$ \\
\hline \multicolumn{3}{|c|}{ Unplanned hospital revisits related to an inadequate request for follow-up a } \\
\hline ED visits & 9 & $1(0.5-2)$ \\
\hline Hospitalisation & 29 & $4(3-6)$ \\
\hline Total unplanned hospital revisits & 38 & $5(4-7)$ \\
\hline
\end{tabular}

Values are number of patients

Abbreviations: $\mathrm{Cl}$ confidence interval, $E D$ emergency department, $M R R$ medication-related referral, $P C P$ primary care provider

${ }^{a}$ Within six months of hospital discharge

a hospital outpatient unit for 189 (27\%) patients, and to both the PCP and a hospital outpatient unit for 69 (10\%) patients. For 240 (34\%) patients, no MRR was sent. The hospitals had sent an adequate request for follow-up for $418(60 \%)$ of the patients. Out of the $281(40 \%)$ patients where the hospitals sent an inadequate request for follow-up, 167 (59\%) had incomplete MRRs sent and 114 (41\%) had no MRR sent, but needed one.

Thirty-eight patients $(5 \%$ of the study population or $14 \%$ of those with an inadequate request sent by the hospitals) had an unplanned hospital revisit within six months of hospital discharge which was related to an inadequate request. Examples of these cases are presented in Table 3.

As shown in Table 4, CMR performed during hospitalisation did not affect the proportion of patients with an adequate or inadequate follow-up request $(p=0.83)$.

\section{Discussion}

This study evaluated the prevalence of patients for whom hospitals sent adequate requests for medication-related follow-up at hospital discharge, regardless of the presence of a CMR during hospitalisation, the proportion of patients who had an unplanned hospital revisit which could be related to an inadequate follow-up request, and the presence of an association between CMRs carried out during hospitalisation and adequate or inadequate requests. We found that requests for follow-up were adequate in $60 \%$ of the patients. Fourteen percent of the patients for whom the hospitals had sent an inadequate request had an unplanned hospital revisit within six months of discharge which could be related to the inadequacy.

The proportion of patients for whom the hospitals sent inadequate requests appears to be substantial and implies poor information transfer at hospital discharge. This is in agreement with previous findings from other countries where up to $50 \%$ of discharge summaries lacked followup planning for medications after hospital discharge $[5,17,20,32]$. Also, for $34 \%$ of the patients, no MRRs were sent at all, despite an MRR was deemed necessary for about half of these patients $(114 / 240)$ to ensure the required follow-up. Medication changes were common, as expected considering the older, multimorbid patient population. Nine out of ten patients had at least one change in their medication treatment and the mean number of changes per patient (3) was well in line with previous studies of the same age group $[6,33,34]$. The high prevalence of medication changes during hospitalisation indicates the importance of a thorough and well 


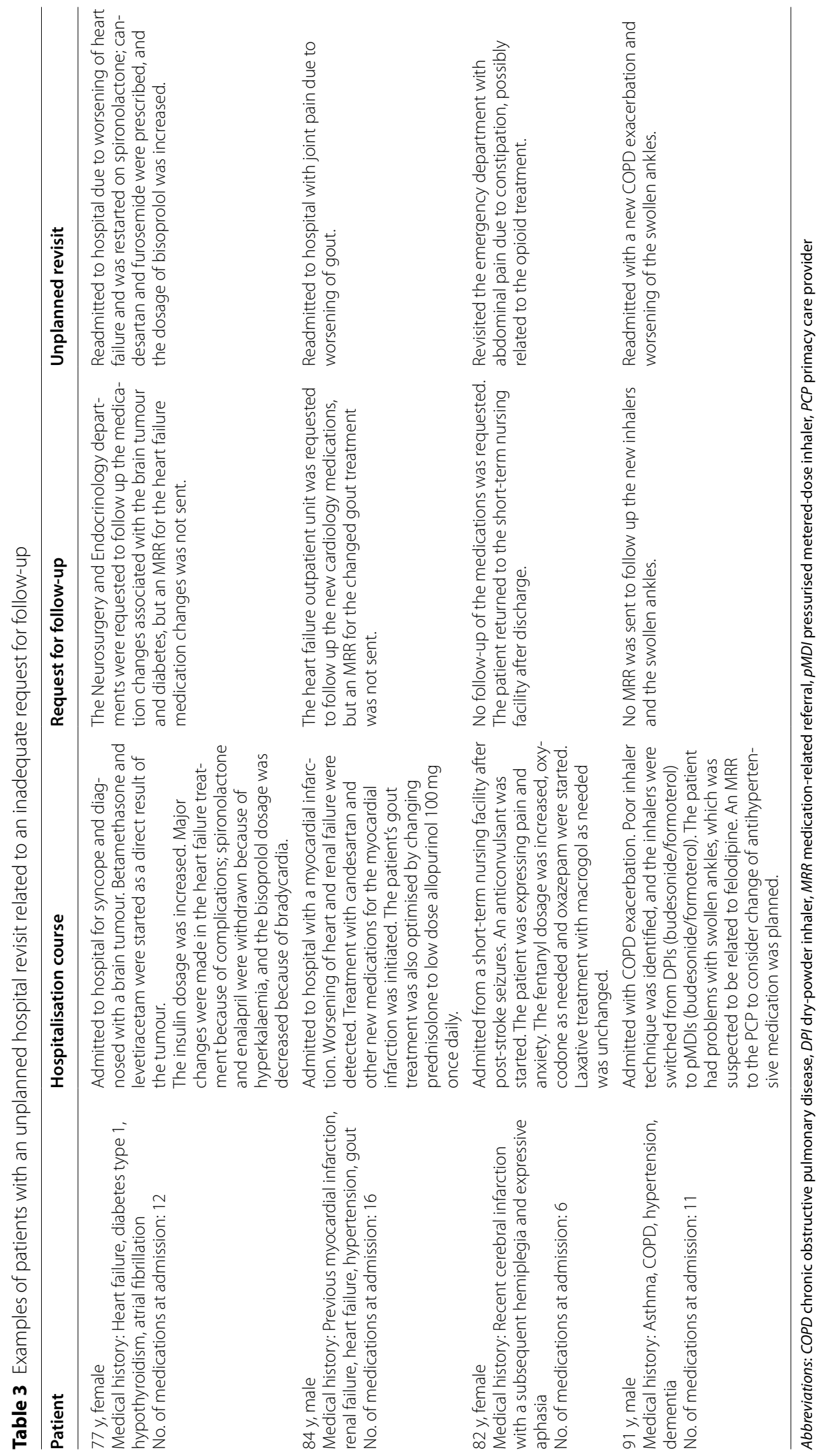


Table 4 Association between adequate/inadequate follow-up requests and patients with or without CMR

\begin{tabular}{llll}
\hline Adequacy of follow-up requests & With CMR & Without CMR & Chi $^{2}$ test of independence \\
\hline Adequate request & $260(37,34-41)$ & $158(23,20-26)$ & $X^{2}(1, n=699)=.04^{\mathrm{a}}$ \\
Inadequate request & $177(25,22-29)$ & $104(15,12-18)$ & 83
\end{tabular}

Values are number of patients $(\%, 95 \mathrm{Cl})$.

Abbreviations: Cl Confidence Interval, CMR Comprehensive Medication Review

$\mathrm{a}=.05$

structured follow-up process after the discharge of older patients. Hospitals should take into consideration that changes in patients' medications often require follow-up to ensure that the changes do not result in adverse outcomes. There could be several reasons for not sending an MRR despite having made changes. The HPs and pharmacists may have intended to send an MRR but forgot, have assessed that follow-up on the changes by the PCP was unnecessary, or (in agreement with the patients or caregivers) have encouraged the patients to approach the PCP themselves after discharge. The discontinuous workflow of hospital physicians caring for patients during hospitalisation could also have contributed to this high proportion of inadequate requests. Discharge summaries and MRRs are sometimes written by physicians who have not been involved in the care of the patients until the day of discharge. The discharge documents are also frequently written by junior physicians with the least experience and with little formal training in writing them $[35,36]$.

Sending MRRs to the PCP or to other healthcare providers, in addition to the more commonly used discharge documents, is likely to be unique to the Swedish healthcare system. This additional administrative step for HPs does not seem to sufficiently enhance the quality of the communication about medications at hospital discharge. Yet PCPs stress the need for being notified after patient hospitalisation to ensure that a follow-up is initiated [19]. The notification does not happen automatically, not even if the patient's medications were changed substantially $[19,37]$. It is unclear if all HPs are aware of this fact. In our study, a shared EHR was used, but a notification in the form of a referral is still requested by the PCP. The high frequency of incomplete MRRs showed that a shared EHR does not automatically solve this problematic communication gap between hospital and PCP. The reason may be that there are no explicit discharge guidelines on when to send an MRR to the PCP after patient hospitalisation, or on what should be included in the MRR. PCPs have highlighted the importance of clear and structured documentation regarding which medications need to be followed up after discharge, and the recommended timing for follow-up [16]. They have also requested information on all the changes made and the reasons for them.
The Royal College of Physicians in the UK has developed guidelines for the structure and content of patient records, including how a request for follow-up after discharge should be written, to mitigate any communication failures [38]. Development and subsequent implementation of equivalent standard guidelines on when and how to write MRRs could enhance their use and quality in a Swedish context.

The high proportion of patients for whom the hospitals sent inadequate requests is worrying since it is then up to the patient or the patient's caregiver for initiating a follow-up of medication changes. It presupposes that the patient or caregiver fully understand what the changes were, why they were carried out, and that follow-up is needed after hospital discharge. For this to happen successfully, the information transfer to the patient or caregiver needs to be clear and correct, which has been shown persistently is not the case [39-41]. The quality of written discharge information to patients is often poor $[39,41]$, and discharge consultations are often performed without clear and sufficient instructions concerning follow-up [42, 43] and are often presented abruptly without preparing the patients for self-management of their medications [44]. In addition, one could argue that the patient or caregiver always has the responsibility for medication treatment and should ask for follow-up if they are not contacted by their PCP after discharge. However, it has been shown that older patients often assume that hospital physicians are obligated to communicate with their PCP and that this communication will be smoothly carried out [45]. It has also been shown that older patients rarely question HPs and assume that they always make the correct decisions [46]. It may therefore be unhelpful to assume that this patient group will initiate contact with the PCP for follow-up of medication changes, unless an obvious side effect occurs. The lack of clear and explicit information about the necessity of follow-up can result in a significant risk of medication-related morbidity.

We found that $5 \%$ of the study population or more than one tenth of the patients for whom the hospitals sent an inadequate request returned to the hospital within six months for reasons that was likely to be connected to the inadequate request. This finding is substantial, and one can see the potential of reducing hospital revisits by 
improving the adequacy of the requests. Previous studies of the effects of discharge documents on hospital revisits have been contradictory. Several earlier studies have not shown an association between poor transfer of discharge documentation and hospital revisits [47-49], but these were conducted during a time and a setting when patients were cared for by their PCP during hospitalisation. A more recent study by Salim et al. showed that better quality discharge documentation could prevent one third of rehospitalisations in patients with heart failure exacerbations [50]. In that study, as in ours, patients were cared for by HPs.

This study is, to our knowledge, the first to investigate an association between CMRs carried out during hospitalisation and inadequate requests sent for follow-up. The fact that no positive link was found indicates that CMRs were not responsible for loss of follow-up after discharge. On the other hand, CMRs did not improve the chances of an adequate request being sent either. The CMRs carried out during hospitalisation in the MedBridge trial were supposed to include a medication reconciliation on hospital discharge. This should have involved a review of all the patient's medications and a check that there was a plan to follow up on all the relevant medication changes made during hospitalisation. However, process evaluation of the MedBridge trial showed that only $50 \%$ of the patients who had a CMR actually received a medication reconciliation at discharge, and only $6 \%$ of the MRRs to PCP were sent by pharmacists performing the CMR [29]. It is important to stress the need to focus on the discharge process when carrying out a CMR during hospitalisation [25], since substantial medication changes may be made as a result. To improve patient safety by improving communications about medication changes to the next healthcare provider, it is not enough to carry out a CMR as in the MedBridge trial. A more focused intervention on the discharge process is needed.

\section{Limitations}

There are some limitations of this study. Firstly, there are limitations associated with retrospective chart reviews. The results were based on what the healthcare professionals wrote in their notes, referrals, and other sections of the EHR - and on our interpretation of these. There may have been valid reasons not to send an MRR to the next healthcare provider which we could not possibly know if they were not documented. We were not able to take into account what was only communicated verbally to a patient. Moreover, there were four researchers involved in the collection of data, and any inconsistencies in assessment may have affected the data quality. We tried to mitigate this by training those involved in data collection and by discussing any unclear cases in an internal expert panel until consensus was reached.

Secondly, we did not investigate how the adequate requests for follow-up were handled by the next healthcare provider: whether the requests were accepted or rejected, or whether and how the follow-up was carried out. An adequate request for follow-up does not automatically mean that the transfer of discharge documentation was unproblematic. The next healthcare provider needs to process and act on the request for follow-up in a correct and timely manner. It has previously been shown that PCPs fail to complete tests and follow-up appointments that the hospital has requested for one quarter of discharged patients [15].

Thirdly, this study design only showed a possible connection between unplanned hospital revisits and patients for whom the hospitals sent inadequate requests for follow-up. An unplanned hospital revisit may have happened even if the request was adequate or if a followup was perfectly carried out. We did not investigate the number of unplanned hospital revisits among patients for whom the hospitals sent adequate requests and, therefore, could not make this comparison.

\section{Implications for research and practice}

This study adds to the evidence of deficiencies in the communication between hospitals and the next healthcare provider on hospital discharge. A problematic communication gap still exists, despite the usage of a shared EHR system between hospital care and primary care. Future research should focus on finding ways to improve the adequacy of requests for follow-up and discharge documentation overall, and to subsequently include these in clinical practice. This study also addresses the need for the development and implementation of guidelines on when and how to write MRRs for hospital discharge.

\section{Conclusions}

In this study of older hospitalised patients, the prevalence of patients for whom the hospitals sent adequate requests for follow-up on discharge was low, and more than one out of ten inadequate requests was associated with an unplanned hospital revisit within six months of discharge. CMRs conducted during hospitalisation did not affect the proportion of patients for whom the hospitals sent inadequate or adequate requests. A problematic communication gap still exists, despite the usage of a shared EHR system between primary and secondary care levels.

\section{Abbreviations}

ADE: Adverse Drug Event; COPD: Chronic obstructive pulmonary disease; CMR: Comprehensive medication review; DRP: Drug-related problem; EHR: 
Electronic health record; HP: Hospital physician; MRR: Medication-related referral; PCP: Primary care provider; SD: Standard deviation.

\section{Acknowledgements}

We would like to acknowledge the other members of our research group for their general support and input into the planning of this study (in alphabetical order): Cecilia Bernsten, Agneta Darberg, Ulf Ehlin, Ellinor Eriksson, Karl-Johan Lindner, Mia Ling, Nils Lannergård Probst, Stina Lindmark, Ingemar Lönnberg, Håkan Melhus, Elisabet Nielsen, Sofia Kälvemark Sporrong, Karin NäslundWestman, Sven-Olov Vestergren, Gerd Waleij and Björn Wennlöf. We would also like to thank the two other students who have been involved in this study (in alphabetical order): Marie Hajbarati and Anne Höglund.

\section{Authors' contributions}

Contributions by each author according to the Contributor Roles Taxonomy (CRediT) [51]: conceptualisation: HC, UG and TK; funding acquisition: UG and TK; formal analysis, project administration and writing - original draft: $\mathrm{HC}$; investigation: $\mathrm{HC}, \mathrm{UG}, \mathrm{HE}$, KA and KF; methodology: $\mathrm{HC}, \mathrm{UG}, \mathrm{TK}$, HE, KA and KF; writing - review \& editing: HC, UG, TK, HE, KA and KF. All authors have read and approved the manuscript.

\section{Funding}

This study was supported by a grant from The Kamprad Foundation for Entrepreneurship, Research \& Charity [Familjen Kamprads stiftelse]. The funding body had no role in the design of the study, the collection, analysis, or interpretation of the data or the writing of the manuscript. Open access funding was provided by Uppsala University.

\section{Availability of data and materials}

The datasets generated and/or analysed during this study are not publicly available since sharing of data was not included in the approval from the ethics committee. However, they are available from the corresponding author on reasonable request. All authors received administrative permission to access and use all the data in this study.

\section{Declarations}

\section{Ethics approval and consent to participate}

This study was part of a larger trial (MedBridge) which was approved by the Swedish Central Ethical Review Board (CEPN; registration number: Ö21-2016). Informed consent was obtained from all participants in the MedBridge trial. All procedures involving data from human participants in this study were carried out in concordance with the ethical standards of Swedish legislation and the WMA declaration of Helsinki [31].

\section{Consent for publication}

Not applicable.

\section{Competing interests}

The authors declare that they have no competing interests.

\section{Author details}

${ }^{1}$ Hospital Pharmacy Department, Uppsala University Hospital, SE-751 85 Uppsala, Sweden. ${ }^{2}$ Department of Pharmacy, Uppsala University, Uppsala, Sweden. ${ }^{3}$ Academic Primary Health Care Centre, Region Uppsala, Uppsala, Sweden. ${ }^{4}$ Geriatric Department, Uppsala University Hospital, Uppsala, Sweden. ${ }^{5}$ Department of Public Health and Caring Sciences, Uppsala University, Uppsala, Sweden.

Received: 7 June 2021 Accepted: 15 October 2021 Published online: 02 November 2021

\section{References}

1. El Morabet N, Uitvlugt EB, van den Bemt BJF, van den Bemt PMLA, Janssen MJA, Karapinar-Çarkit F. Prevalence and Preventability of DrugRelated Hospital Readmissions: A Systematic Review. J Am Geriatr Soc 03. 2018;66:602-8. https://doi.org/10.1111/jgs.15244.
2. Oscanoa TJ, Lizaraso F, Carvajal A. Hospital admissions due to adverse drug reactions in the elderly. A meta-analysis. Eur J Clin Pharmacol. 2017;73:759-70. https://doi.org/10.1007/s00228-017-2225-3.

3. Alhawassi TM, Krass I, Bajorek BV, Pont LG. A systematic review of the prevalence and risk factors for adverse drug reactions in the elderly in the acute care setting. Clin Interv Aging. 2014;9:2079-86 https://doi.org/10. 2147/CIA.S71178.

4. World Health Organization. Transitions of Care: Technical Series on Safer Primary Care 2016. http://www.who.int/patientsafety/topics/primarycare/technical_series/en/ (Accessed 25 March 2021).

5. Kripalani S, LeFevre F, Phillips CO, Williams MV, Basaviah P, Baker DW. Deficits in communication and information transfer between hospitalbased and primary care physicians: implications for patient safety and continuity of care. JAMA. 2007;297:831-41. https://doi.org/10.1001/jama. 297.8.831.

6. Blozik E, Signorell A, Reich O. How does hospitalization affect continuity of drug therapy: an exploratory study. Ther Clin Risk Manag. 2016;12:1277-83. https://doi.org/10.2147/tcrm.s109214.

7. Coleman EA, Smith JD, Raha D, Min S-J. Posthospital medication discrepancies: prevalence and contributing factors. Arch Intern Med. 2005;165:1842-7. https://doi.org/10.1001/archinte.165.16.1842.

8. Armor BL, Wight AJ, Carter SM. Evaluation of adverse drug events and medication discrepancies in transitions of care between hospital discharge and primary care follow-up. J Pharm Pract. 2016;29:132-7. https:// doi.org/10.1177/0897190014549836.

9. Midlöv P, Bergkvist A, Bondesson A, Eriksson T, Höglund P. Medication errors when transferring elderly patients between primary health care and hospital care. Pharm World Sci. 2005;27:116-20. https://doi.org/10. 1007/s11096-004-3705-y.

10. Alassaad A, Gillespie U, Bertilsson M, Melhus H, Hammarlund-Udenaes M. Prescription and transcription errors in multidose-dispensed medications on discharge from hospital: an observational and interventional study. J Eval Clin Pract. 2013;19:185-91. https://doi.org/10.1111/j.1365-2753.2011. 01798.x.

11. World Health Organization. Patient Engagement:Technical Series on Safer Primary Care 2016. http://apps.who.int/iris/bitstream/handle/ 10665/252269/9789241511629-eng.pdf?sequence=1 (Accessed 18 April 2021).

12. Region Uppsala Utskrivning från slutenvård [Hospital discharge]. Region Uppsala 2019. https://publikdocplus.regionuppsala.se/ (Accessed 25 March 2021).

13. National Board of Health and Welfare. Socialstyrelsens föreskrifter och allmänna råd om ordination och hantering av läkemedel i hälso och sjukvården [The National Board of Health and Welfare's regulations and general guidelines on prescribing and handling of medications in health care]. Socialstyrelsen 2017. https://www.socialstyrelsen.se/regler-och-riktl injer/foreskrifter-och-allmanna-rad/konsoliderade-foreskrifter/201737om-ordination-och-hantering-av-lakemedel-i-halso\%2D\%2Doch-sjukv arden/ (Accessed 24 March 2021).

14. Mughal Z, Maharjan R. Cross-sectional analysis of hospital tasks handed over to general practitioners: workload delegation or dumping? Postgrad Med J. 2021. https://doi.org/10.1136/postgradmedj-2020-139641.

15. Spencer RA, Spencer SEF, Rodgers S, Campbell SM, Avery AJ. Processing of discharge summaries in general practice: a retrospective record review. Br J Gen Pract. 2018:68:e576-85. https://doi.org/10.3399/bjgp18X697877.

16. Weetman K, Dale J, Spencer R, Scott E, Schnurr S. GP perspectives on hospital discharge letters: an interview and focus group study. BJGP Open. 2020;4. https://doi.org/10.3399/bjgpopen20X101031.

17. Horwitz LI, Jenq GY, Brewster UC, Chen C, Kanade S, Van Ness PH, et al. Comprehensive quality of discharge summaries at an academic medical center. J Hosp Med. 2013;8:436-43. https://doi.org/10.1002/jhm.2021.

18. Schwarz CM, Hoffmann M, Schwarz P, Kamolz L-P, Brunner G, Sendlhofer G. A systematic literature review and narrative synthesis on the risks of medical discharge letters for patients' safety. BMC Health Serv Res. 2019;19:158. https://doi.org/10.1186/s12913-019-3989-1.

19. Caleres G, Strandberg EL, Bondesson Å, Midlöv P, Modig S. Drugs, distrust and dialogue -a focus group study with Swedish GPs on discharge summary use in primary care. BMC Fam Pract. 2018;19:127. https://doi.org/10. 1186/s12875-018-0804-8.

20. Mette FKB. Kommunikasjon om medikamentbruk i henvisninger, innleggelsesskriv og epikriser [Communication about drug use in referrals, 
acute admissions and discharge letters]. Tidsskr Nor Legeforen Nr. 2011;9:10. https://doi.org/10.4045/tidsskr.10.0728.

21. McMillan TE, Allan W, Black PN. Accuracy of information on medicines in hospital discharge summaries. Intern Med J. 2006;36:221-5. https://doi. org/10.1111/j.1445-5994.2006.01028.x.

22. Region Uppsala and the municipalities of Uppsala. Samverkan vid utskrivning från slutenvård [Collaboration upon hospital discharge] 2021. https://publikdocplus.regionuppsala.se/ (Accessed 25 March 2021).

23. Dautzenberg L, Bretagne L, Koek HL, Tsokani S, Zevgiti S, Rodondi N, et al. Medication review interventions to reduce hospital readmissions in older people. J Am Geriatr Soc. 2021. https://doi.org/10.1111/jgs.17041.

24. Gillespie U, Alassaad A, Henrohn D, Garmo H, Hammarlund-Udenaes M, Toss $\mathrm{H}$, et al. A comprehensive pharmacist intervention to reduce morbidity in patients 80 years or older: a randomized controlled trial. Arch Intern Med. 2009;169:894-900. https://doi.org/10.1001/archinternmed. 2009.71.

25. Ravn-Nielsen LV, Duckert M-L, Lund ML, Henriksen JP, Nielsen ML, Eriksen CS, et al. Effect of an in-hospital multifaceted clinical pharmacist intervention on the risk of readmission: a randomized clinical trial. JAMA Intern Med. 2018;178:375-82. https://doi.org/10.1001/jamainternmed.2017. 8274.

26. NICE Medicines and Prescribing Centre (UK). Medicines Optimisation: The Safe and Effective Use of Medicines to Enable the Best Possible Outcomes. Manchester: National Institute for Health and Care Excellence (UK); 2015.

27. Griese-Mammen N, Hersberger KE, Messerli M, Leikola S, Horvat N, van Mil JWF, et al. PCNE definition of medication review: reaching agreement. Int J Clin Pharm. 2018;40:1199-208. https://doi.org/10.1007/ s11096-018-0696-7.

28. Kempen TGH, Bertilsson M, Hadziosmanovic N, Lindner K-J, Melhus $\mathrm{H}$, Nielsen El, et al. Effects of hospital-based comprehensive medication reviews including Postdischarge follow-up on older patients' use of health care: a cluster randomized clinical trial. JAMA Netw Open. 2021;4:e216303. https://doi.org/10.1001/jamanetworkopen.2021.6303.

29. Kempen TGH, Cam H, Kälvemark A, Lindner K-J, Melhus H, Nielsen El, et al. Intervention fidelity and process outcomes of medication reviews including post-discharge follow-up in older hospitalized patients: process evaluation of the MedBridge trial. J Clin Pharm Ther. 2020;45:1021-9. https://doi.org/10.1111/jcpt.13128.

30. Database - Eurostat. Eurostat n.d. https://ec.europa.eu/eurostat/data/ database (Accessed 29 March 2021).

31. World Medical Association. World medical association declaration of Helsinki: ethical principles for medical research involving human subjects. JAMA. 2013;310:2191-4. https://doi.org/10.1001/jama.2013.281053.

32. Tan B, Mulo B, Skinner M. Transition from hospital to primary care: an audit of discharge summary - medication changes and follow-up expectations. Intern Med J. 2014;44:1124-7. https://doi.org/10.1111/imj.12581.

33. Graabæk T, Terkildsen BG, Lauritsen KE, Almarsdóttir AB. Frequency of undocumented medication discrepancies in discharge letters after hospitalization of older patients: a clinical record review study. Ther Adv Drug Saf. 2019;10:1-8 https://doi.org/10.1177/2042098619858049.

34. Himmel W, Kochen MM, Sorns U, Hummers-Pradier E. Drug changes at the interface between primary and secondary care. Int J Clin Pharmacol Ther. 2004;42:103-9. https://doi.org/10.5414/cpp42103.

35. Wimble K, Yeong K. Improving patient follow-up after inpatient stay. BMJ Qual Improv Rep. 2012;1. https://doi.org/10.1136/bmjquality.u474.w148,

36. Cresswell A, Hart M, Suchanek O, Young T, Leaver L, Hibbs S. Mind the gap: improving discharge communication between secondary and primary care. BMJ Qual Improv Rep. 2015;4. https://doi.org/10.1136/bmjqu ality.u207936.w3197.

37. Strehlau AG, Larsen MD, Søndergaard J, Almarsdóttir AB, Rosholm J-U. General practitioners' continuation and acceptance of medication changes at sectorial transitions of geriatric patients - a qualitative interview study. BMC Fam Pract. 2018:19:168. https://doi.org/10.1186/ s12875-018-0855-x.
38. Professional Record Standards Body. The PRSB standards for the structure and content of health and care records. Royal College of Physicians 2018. https://www.rcplondon.ac.uk/projects/outputs/standards-clinical-struc ture-and-content-patient-records (Accessed 7 April 2021).

39. Caleres G, Bondesson Å, Midlöv P, Modig S. Elderly at risk in care transitions when discharge summaries are poorly transferred and used -a descriptive study. BMC Health Serv Res. 2018;18:770. https://doi.org/10. 1186/s12913-018-3581-0.

40. Caleres G, Modig S, Midlöv P, Chalmers J, Bondesson Å. Medication discrepancies in discharge summaries and associated risk factors for elderly patients with many drugs. Drugs Real World Outcomes. 2020;7:53-62. https://doi.org/10.1007/s40801-019-00176-5.

41. Meyer-Massetti C, Hofstetter V, Hedinger-Grogg B, Meier CR, Guglielmo BJ. Medication-related problems during transfer from hospital to home care: baseline data from Switzerland. Int J Clin Pharm. 2018;40:1614-20. https://doi.org/10.1007/s11096-018-0728-3.

42. Hesselink G, Flink M, Olsson M, Barach P, Dudzik-Urbaniak E, Orrego C, et al. Are patients discharged with care? A qualitative study of perceptions and experiences of patients, family members and care providers. BMJ Qual Saf. 2012;21(Suppl 1):i39-49. https://doi.org/10.1136/ bmjgs-2012-001165.

43. Siddiqui TG, Cheng S, Mellingsæter M, Grambaite R, Gulbrandsen P, Lundqvist C, et al. 'What should I do when I get home?'Treatment plan discussion at discharge between specialist physicians and older in-patients: mixed method study. BMC Health Serv Res. 2020;20:1002. https://doi.org/ 10.1186/s12913-020-05860-9.

44. Rognan SE, Sporrong SK, Bengtsson K, Lie HB, Andersson Y, Mowé M, et al. Discharge processes and medicines communication from the patient perspective: a qualitative study at an internal medicines ward in Norway. Health Expect. 2021. https://doi.org/10.1111/hex.13232.

45. Arora VM, Prochaska ML, Farnan JM, Darcy MJ 5th, Schwanz KJ, Vinci LM, et al. Problems after discharge and understanding of communication with their primary care physicians among hospitalized seniors: a mixed methods study. J Hosp Med. 2010;5:385-91. https://doi.org/10.1002/jhm. 668.

46. Ekdahl AW, Andersson L, Friedrichsen M.'They do what they think is the best for me.' Frail elderly patients' preferences for participation in their care during hospitalization. Patient Educ Couns. 2010;80:233-40. https:// doi.org/10.1016/j.pec.2009.10.026.

47. Walraven C, Seth R, Austin PC, Laupacis A. Effect of discharge summary availability during post-discharge visits on hospital readmission. J Gen Intern Med. 2002;17:186-92. https://doi.org/10.1046/j.1525-1497.2002. 10741.X.

48. Bell CM, Schnipper JL, Auerbach AD, Kaboli PJ, Wetterneck TB, Gonzales DV, et al. Association of communication between hospital-based physicians and primary care providers with patient outcomes. J Gen Intern Med. 2009;24:381-6 https://doi.org/10.1007/s11606-008-0882-8.

49. Hansen LO, Strater A, Smith L, Lee J, Press R, Ward N, et al. Hospital discharge documentation and risk of rehospitalisation. BMJ Qual Saf. 2011;20:773-8. https://doi.org/10.1136/bmjqs.2010.048470.

50. Salim Al-Damluji M, Dzara K, Hodshon B, Punnanithinont N, Krumholz HM, Chaudhry SI, et al. Association of discharge summary quality with readmission risk for patients hospitalized with heart failure exacerbation. Circ Cardiovasc Qual Outcomes. 2015;8:109-11. https://doi.org/10.1161/ CIRCOUTCOMES.114.001476.

51. CASRAI. CRediT - Contributor Roles Taxonomy 2019. https://casrai.org/ credit/ (Accessed 7 April 2021).

\section{Publisher's Note}

Springer Nature remains neutral with regard to jurisdictional claims in published maps and institutional affiliations. 